\title{
Robot - assisted laparoscopic retroperitoneal lymph node dissection in testicular tumor
}

\author{
Fabio C. M. Torricelli ${ }^{1}$, Denis Jardim ${ }^{2}$, Giuliano B. Guglielmetti ${ }^{2}$, Vipul Patel ${ }^{3}$, Rafael F. Coelho ${ }^{2}$ \\ ${ }^{1}$ Hospital das Clínicas da Faculdade de Medicina da Universidade de São Paulo, SP, Brasil; ${ }^{2}$ Instituto \\ do Câncer do Estado de São Paulo (ICESP), SP, Brasil; ${ }^{3}$ Global Robotics Institute, Orlando, Florida, EUA
}

\section{ABSTRACT}

Introduction and objective: Retroperitoneal lymph node dissection (RPLND) is indicated for patients with non-seminomatous germ cell tumor (NSGCT) with residual disease after chemotherapy. Although the gold standard approach is still the open surgery, few cases of robot-assisted laparoscopic RPLND have been described. Herein, we aim to present the surgical technique for robot-assisted laparoscopic RPLND.

Patient and method: A 30 year-old asymptomatic man presented with left testicular swelling for 2 months. Physical examination revealed an enlarged and hard left testis. Alpha-fetoprotein $(>1000 \mathrm{ng} / \mathrm{mL}$ ) and beta-HCG (>24.000U/L) were increased. Beta-HCG increased to $>112.000 \mathrm{U} / \mathrm{L}$ in less than one month. The patient underwent a left orchiectomy. Pathological examination showed a mixed NSGCT (50\% embryonal carcinoma; 30\% teratoma; 10\% yolk sac; 10\% choriocarcinoma). Computed tomography scan revealed a large tumor mass close to the left renal hilum (10x4x4cm) and others enlarged paracaval and paraortic lymph nodes (T2N3M1S3-stage III). Patient was submitted to 4 cycles of BEP with satisfactory response. Residual mass was suggestive of teratoma. Based on these findings, he was submitted to a robot-assisted RPLND.

Results: RPLND was uneventfully performed. Operative time was 3.5 hours. Blood loss was minimal, and there were no intra- or postoperative complications. The patient was discharged from hospital in the $1^{\text {st }}$ postoperative day. Pathological examination showed a pure teratoma. After 6 months of follow-up, patient is asymptomatic with an alpha-fetoprotein of 2.9ng/mL and an undetectable beta-HCG.

Conclusion: Robot-assisted laparoscopic RPLND is a feasible procedure with acceptable morbidity even for post chemotherapy patients when performed by an experienced surgeon.

\section{ARTICLE INFO}

Available at: http://www.intbrazjurol.com.br/video-section/torricelli_171_171/

Int Braz J Urol. 2017; 43 (Video \#3): 171-171

Submitted for publication:

August 09, 2015

Accepted after revision:

December 21, 2015

Published as Ahead of Print:

September 09, 2016
Correspondence address:

Fábio César Miranda Torricelli, MD Av. Vereador José Diniz, 3300, conjunto 208 04604-006, São Paulo, SP Tel.: + 5511 5533-4900 E-mail: fabio_torri@yahoo.com.br 